\title{
AGRICULTURA FAMILIAR E SEGURANÇA ALIMENTAR E NUTRICIONAL: UM ESTUDO SOBRE A RELAÇÃO PRODUÇÃO-CONSUMO NOS MUNICIPIOS DE TOLEDO (PR) E CONTAGEM (MG)
}

\author{
Irio Luiz Conti ${ }^{1}$ \\ Angelita Bazotti ${ }^{2}$ \\ Guilherme F. W. Radomsky
}

\section{Resumo}

O artigo visa contribuir com o debate sobre o potencial da agricultura familiar para o fortalecimento de um modelo de produção e consumo que garanta a segurança alimentar e nutricional da população. Utilizou-se a abordagem qualitativa apoiada em técnicas de pesquisa documental, observação participante e entrevistas semiestruturadas para a obtenção dos dados secundários e primários deste estudo. Inicialmente reúnem-se contribuições de especialistas sobre o contexto internacional da agricultura e da segurança alimentar e nutricional e, na sequência, relaciona-se a emergência da agricultura familiar brasileira e o debate sobre produção de alimentos. Apresentam-se dados do Censo Agropecuário que corroboram que a agricultura familiar, que responde por $84,4 \%$ dos estabelecimentos rurais do país, é responsável por quase $80 \%$ da produção dos alimentos. Com apenas $24,3 \%$ do total da área dos estabelecimentos a agricultura familiar responde por $33,2 \%$ do valor geral da produção e mantém $74,4 \%$ dos trabalhadores ocupados nos estabelecimentos. Analisam-se dois casos de articulação entre rural e urbano, nos municípios de Toledo e Contagem, que mostram a reconfiguração

\footnotetext{
${ }^{1}$ Graduado em Teologia pelo Instituto Missioneiro de Teologia com licenciatura em Filosofia (UPF). Especialista em Direitos Humanos (CESUSC). Mestre em Sociologia (UFRGS). Doutorando em Desenvolvimento Rural (PGDR/UFRGS). Conselheiro do Conselho Nacional de Segurança Alimentar e Nutricional (CONSEA). Bolsista FAPERGS.

2 Graduada em Ciências Políticas e Sociais. Mestrado em Sociologia (UFPR). Doutoranda em Desenvolvimento Rural (PGDR/UFRGS). Pesquisadora do Instituto Paranaense de Desenvolvimento Econômico e Social (IPARDES).

3 Graduado em Ciências Sociais (UFRGS). Mestrado em Desenvolvimento Rural (UFRGS). Doutorado em Antropologia Social (PPGAS/UFRGS). Professor Adjunto da Universidade Federal do Rio Grande do Sul.
} 
das relações entre produção e consumo de alimentos a partir do papel proativo dos atores sociais e do Estado.

Palavras-chave: agricultura familiar; segurança alimentar e nutricional; produção; consumo; ruralidade.

\title{
FAMILY FARMING AND FOOD AND NUTRITIONAL SECURITY: A STUDY ON PRODUCTION-CONSUMPTION RELATIONSHIP FROM THE CASES OF TOLEDO (PR) AND CONTAGEM (MG) MUNICIPALITIES
}

\begin{abstract}
The article's aim is to enhance the debate about the potential of family farming to the strengthening of a production-consumption model that ensures food and nutritional security for the population. The research was based on a qualitative approach, including documents analysis, participant observation and interviews. At first, we gather expert contributions about international context over agriculture and food and nutritional security and relate these to the emergence of family farming in Brazil and food production debate. Data from Brazilian Agricultural Census are analyzed and states that family farming, which covers $84,4 \%$ of rural units, is responsible for almost $80 \%$ of food production. Having only $24,3 \%$ of total amount of lands (ha), family farming produces $33,2 \%$ of general production holding $74,4 \%$ of occupied labor. We examine two situations (Toledo and Contagem municipalities) that show rural-urban articulation and reveal the reconfiguration of food production-consumption relationship through the active role of social actors and the State.
\end{abstract}

Key-words: family farming; food and nutritional security; production; consumption; rurality. 


\section{INTRODUÇÃO}

O espaço da agricultura familiar no sistema agroalimentar tem sido objeto de intensos debates nos meios acadêmicos e sociais. Para alguns, a modernização da agricultura e 0 aperfeiçoamento tecnológico com automação crescente e redução drástica da mão-de-obra apontam para a agricultura do futuro. A correção de pequenas distorções, especialmente relacionadas à sustentabilidade ambiental e ao aumento da produtividade agrícola, responderia às demandas de produção e abastecimento alimentar baseadas no modelo agroindustrial e exportador.

Para outros, porém, o cenário é diferente. O modelo acima referido estaria superado e emergeriam múltiplas formas de organização social baseadas na agricultura familiar e no rural com gente, que exerceria um papel relevante na produção de alimentos para o autoconsumo e para o abastecimento alimentar.

Este artigo tem por objetivo contribuir com o debate sobre o potencial da agricultura familiar para fortalecer um modelo de produção e consumo alimentar que garanta a realização da segurança alimentar e nutricional ${ }^{4}$ da população no Brasil. Ao longo deste estudo será possível demonstrar que, em diferentes contextos, a agricultura familiar contribui para viabilizar formas de vida no espaço rural, ao mesmo tempo em que oportuniza sinergias e aproximações entre o rural e o urbano na produção e consumo alimentar. Isso será mais evidenciado com os dois casos que mostram que o Estado e a sociedade civil, pluralizada em esferas de atuação, constituem dois polos complementares na implementação de políticas públicas de segurança alimentar e nutricional (SAN).

Inicialmente reúnem-se contribuições de especialistas sobre as perspectivas da agricultura e da segurança alimentar e nutricional no mundo. Na sequência, relacionam-se a emergência da agricultura familiar no Brasil e dois casos que evidenciam sua importância para garantir a segurança alimentar e nutricional com alimentos saudáveis.

\footnotetext{
${ }^{4}$ Entre os objetivos e diretrizes que regem a Política Nacional de Segurança Alimentar e Nutricional destacam-se: a universalidade e a equidade no acesso à alimentação adequada; a promoção do abastecimento e a estruturação de sistemas sustentáveis e descentralizados; processos permanentes de educação alimentar e nutricional; universalização e coordenação das ações de SAN voltadas para quilombolas e demais povos e comunidades tradicionais; o acesso universal à água de qualidade e em quantidade; participação e controle social na formulação e execução das políticas; intersetorialidade das políticas; e o monitoramento da realização do direito humano à alimentação adequada (CONSEA, 2004; BRASIL, 2010, art. 2º).
} 
Os casos apresentados são dos municípios de Contagem, em Minas Gerais, e Toledo, no Paraná ${ }^{5}$. O primeiro ilustra a realidade de um centro metropolitano em torno do incentivo à produção para ampliar a segurança alimentar e nutricional de sua população. O segundo demonstra a preocupação dos diferentes atores com políticas públicas que reforcem e viabilizem a agricultura familiar, por meio do fortalecimento da conexão entre produtores e consumidores. Ambos os casos se interconectam com a implantação da Política e do Sistema Nacional de Segurança Alimentar e Nutricional (SISAN) ${ }^{6}$ em sua dimensão municipal.

A coleta de dados ${ }^{7}$ foi obtida por meio de fontes secundárias e primárias. Inicialmente foram recolhidos e analisados diversos documentos dos órgãos públicos e das organizações e entidades sociais sobre as políticas e programas de SAN em seus diversos estágios de implantação. Na sequência fez-se a coleta dos dados primários mediante a utilização de duas técnicas de pesquisa: a observação participante e as entrevistas semiestruturadas.

A observação participante foi utilizada em reuniões com gestores públicos e lideranças das organizações e associações da agricultura familiar. Já as entrevistas semiestruturadas ocorreram com as lideranças das organizações sociais da agricultura familiar, das entidades e com os gestores públicos como prefeitos, secretários, coordenadores de setores e nutricionistas que possuem algum vínculo com as politicas de SAN nos municípios. Priorizou-se a abordagem qualitativa e a questão central que orientou ambas as técnicas foi conhecer as experiências e os atores locais, com enfoque no potencial dos programas e ações de SAN para dinamizar as interfaces entre a produção e o consumo nos municípios.

Nas entrevistas foram ouvidas lideranças de quatro organizações da agricultura familiar e de duas da agricultura periurbana envolvidas com o processo de produção e abastecimento dos programas públicos de compras institucionais como o Programa de Aquisição de Alimentos (PAA) e o Programa Nacional de Alimentação Escolar (PNAE); dirigentes de 12 instituições socioassistenciais e educativas que recebem e distribuem os alimentos oriundos desses programas; sete gestores públicos (prefeitos e secretários municipais), dois membros do Conselho

\footnotetext{
${ }^{5}$ A versão ampliada deste estudo faz parte do Relatório de pesquisa denominado "Sistemas Descentralizados de Segurança Alimentar e Nutricional", elaborado por Irio Luiz Conti, Mariana Santarelli e Telma Castello Branco, em 2011, para o Ministério do Desenvolvimento Social e Combate à Fome.

${ }_{7}^{6}$ O SISAN foi instituído pela Lei 11.346/2006.

${ }^{7}$ As visitas de campo foram realizadas no segundo semestre de 2010 e atualizadas com informações obtidas no primeiro semestre de 2011.
} 
Municipal de Segurança Alimentar e Nutricional (COMSEA) em cada município, dois coordenadores do departamento de SAN e 11 técnicos responsáveis pela operacionalização dos referidos programas nos municípios. Na sequência fez-se a sistematização e análise dos dois casos, com alguns aprendizados que podem trazer aportes para as interfaces entre agricultura familiar e segurança alimentar e nutricional.

\section{AGRICULTURA E SEGURANÇA ALIMENTAR E NUTRICIONAL NO DEBATE INTERNACIONAL}

A preocupação em torno da agricultura familiar e da alimentação não é apenas regional e nacional, mas também mundial. $A$ realidade internacional em relação à segurança alimentar e nutricional evidencia que coexistem situações de má nutrição, que vão desde a fome ${ }^{8}$ até a obesidade, afetando tanto os países desenvolvidos quanto os em desenvolvimento.

Com a emergência da crise internacional do sistema agroalimentar, em 2008, no contexto das crises econômica, energética e ambiental, a Organização das Nações Unidas para a Alimentação e Agricultura $(F A O)^{9}$ identificou alguns temas indispensáveis para o enfrentamento da crise alimentar, tais como: a alimentação e a agricultura; as mudanças agrícolas e agrárias, seus entornos macroeconômicos, os mercados agroalimentares e os preços dos alimentos; pobreza e desigualdades sociais; acesso à base de recursos como água, terra, bosques e potencial genético; mudanças climáticas, investimentos públicos e privados para reverter à crise alimentar nos países desenvolvidos e em desenvolvimento; políticas de segurança alimentar e nutricional; e modelos de desenvolvimento, especialmente na África. Esses temas mostram que a crise do sistema alimentar intensificou preocupações convergentes em torno do papel central da agricultura familiar na produção e abastecimento alimentar.

Com a contribuição de diferentes especialistas, a agricultura e a SAN ocupam amplos espaços na literatura acadêmica e nos

\footnotetext{
${ }^{8}$ Segundo a FAO o número de pessoas famintas no mundo é de 870 milhões e a partir de 2011 o número de obesos ultrapassou o número de pessoas famintas e alcançou 1,5 milhão.

${ }^{9}$ Em 2008 a FAO criou o Painel de Expertos de Alto Nível em Segurança Alimentar e Nutricional (HLPE) no interior do Comitê de Segurança Alimentar e Nutricional (CFS) para contribuir com o CFS em análises sobre a situação da SAN no mundo. Este Painel apresentou seus estudos em junho de 2009, em Roma, com o tema: "Como alimentar o mundo em 2050?". Ver "Foro de Expertos de Alto Nível". Disponível em: http://www.fao.org/wsfs/forum2050/wsfs-background-documents/wsfs-expert-papers/es/
} 
debates dos organismos internacionais que avaliam e recomendam políticas e iniciativas relacionadas ao sistema agroalimentar. Recentemente quatro documentos foram divulgados no âmbito das Nações Unidas. Um foi elaborado por Olivier de Schutter, intitulado Agroecologia e o Direito Humano à Alimentação Adequada, e apresentado à Comissão de Direitos Humanos da ONU. Outros dois foram preparados pelo Painel de Expertos de Alto Nível em Segurança Alimentar e Nutricionais (HLPE/CFS/FAO) e denominados, respectivamente, de Segurança Alimentar e Mudança Climática (FAO, 2012a) e Proteção Social para a Segurança Alimentar ( $F A O, 2012 b)$. O último é o relatório anual da FAO sobre $O$ Estado Mundial da Agricultura e a Alimentação (FAO, 2013). Dada a sua relevância, faz-se uma breve retomada destes documentos e seus aportes centrais ao debate sobre a agricultura e a segurança alimentar e nutricional em âmbito internacional.

O relator da ONU ressalta que a retomada dos investimentos na agricultura após a crise de 2008 é um fator essencial à plena realização do direito à alimentação. Entretanto, destaca que a questão mais premente não se localiza no "quanto" os países podem e devem investir, mas sim "como" deverão reorientar seus sistemas agroalimentares de modo que sejam produtivos e sustentáveis. Schutter (2012, p. 9) identifica a "agroecologia como um meio de desenvolvimento que apresenta fortes conexões conceituais com 0 direito à alimentação e tem resultados comprovados" na realização deste direito na vida de muitos grupos sociais. Pois, sua abordagem sistêmica e holística proporciona vantagens complementares às abordagens convencionais por possibilitar compreensões da diversidade que integra os agroecossistemas com suas variedades e seus potenciais de produtividade, que ultrapassam a estrita dimensão do desenvolvimento econômico e abrangem relações mais equilibradas entre o ser humano e os diversos usos dos recursos naturais.

Segundo Schutter (2012), os países signatários dos acordos e tratados internacionais de direitos humanos assumem as obrigações de adotar medidas eficazes para superar a pobreza especialmente presente nas áreas rurais ${ }^{10}$ - e garantir a realização do direito humano à alimentação, mediante a implantação de sistemas alimentares que cumpram três objetivos estratégicos.

\footnotetext{
10 Segundo a FIAN Internacional, as pessoas que padecem pela fome no mundo encontram-se majoritariamente em zonas rurais, assim agrupadas: $50 \%$ são agricultores em pequena escala, $20 \%$ são trabalhadores agrícolas sem terra, $10 \%$ são pastores, pescadores e habitantes de bosques que dependem dos recursos naturais para viver e os outros $20 \%$ vivem nas zonas urbanas.
} 
O primeiro requer que os sistemas alimentares garantam a disponibilidade de alimentos para toda população mundial de modo a adequar a oferta às demandas mundiais, por meio da adoção de tecnologias sustentáveis, redução de desperdícios ${ }^{11}$ e o reordenamento da produção e do consumo. O segundo destaca que a agricultura precisa adotar medidas que evitem a perda da biodiversidade, o uso desregrado da água, a crescente contaminação dos solos e das águas e a exaustão dos recursos naturais. $\mathrm{E}$ o terceiro objetivo aponta que as causas da fome decorrem da pobreza e não da falta de alimentos e a forma mais eficiente de combatê-la seria aumentar a renda dos mais pobres, visto que o PIB agrícola é, no mínimo, duas vezes mais eficaz na redução da pobreza do que o crescimento do PIB fora da agricultura.

Os efeitos multiplicadores são
significativamente maiores quando o
crescimento é desencadeado pela maior
renda dos pequenos proprietários,
estimulando a demanda por produtos e
serviços de vendedores e prestadores de
serviços locais. Quando as grandes
propriedades aumentam sua receita, a maior
parte dela é investida em insumos e
máquinas importadas e uma parte muito
menor vai para os comerciantes locais.
Apenas ao apoiarmos os pequenos
produtores nós poderemos ajudar a romper o
círculo vicioso que leva da pobreza rural à
expansão de favelas urbanas, nas quais a
pobreza gera mais pobreza (SCHUTTER,
2012, p. 15).

No documento sobre Segurança Alimentar e Mudança Climática, o Painel de Expertos em Segurança Alimentar e Nutricional da FAO (2012a) aponta que os desafios para a agricultura e SAN tornam-se mais complexos diante da insuficiência de recursos disponibilizados pela maioria dos Estados para mitigar esta situação e das mudanças climáticas que reduzem a capacidade de produção $e$, consequentemente, aumentam a vulnerabilidade e a insegurança

\footnotetext{
11 Segundo a FAO (2013) ao redor de um terço da produção agrícola mundial é desperdiçada.
} 
alimentar e nutricional das regiões mais expostas a tais fatores. Diante disso é necessário que haja um manejo de riscos, acompanhado de estratégias de construção de sistemas alimentares e estímulo a processos de produção, processamento e consumo mais resilientes e ancorados nas características dos ecossistemas locais e regionais. Entre as estratégias recomendadas encontram-se o aperfeiçoamento de infraestrutura; a captura e manejo das águas, com tecnologias sociais de irrigação; a produção orgânica; a qualificação de sistemas de armazenagem e a redução de desperdício em toda cadeia de produção; a reconversão do uso de cereais para à alimentação humana e não animal. Igualmente são necessários volumosos investimentos públicos em pesquisas que contribuam com tecnologias agrícolas adaptadas às condições adversas que mitiguem os impactos das mudanças climáticas, além de crédito e serviços de extensão rural que estimulem a produção agroalimentar.

O terceiro texto, também produzido pelo Painel de Expertos $^{12}$ da FAO (2012b), enfoca a Proteção Social para a Segurança Alimentar e Nutricional. Os especialistas avaliam as políticas de proteção social na agenda de desenvolvimento e apontam a importância das mesmas serem desenvolvidas de forma sistêmica e cada vez mais intersetorial, com a conjugação de medidas imediatas e mudanças estruturais, como a criação de empregos, acesso a recursos produtivos e dinamização da agricultura familiar. Como as causas da insegurança alimentar e nutricional são multifatoriais os especialistas frisam que elas precisam ser enfrentadas com medidas interrelacionadas como: criação de empregos e viabilização do acesso a terra, à água e aos recursos naturais; viabilização de sistemas públicos de abastecimento e gestão de estoque de alimentos; e criação de condições de acesso ao mercado desde a perspectiva do consumo, do suprimento e da regulação de preços dos alimentos.

A publicação da FAO sobre O Estado Mundial da Agricultura e a Alimentação (FAO, 2013) evidencia que a má nutrição subnutrição, deficiência de micronutrientes, sobrepeso e obesidade acarreta altos custos econômicos e sociais aos países ${ }^{13}$. Acentua que uma boa nutrição e dietas saudáveis começam com alimentação e agricultura de qualidade, baseadas em múltiplas estratégias, tais

\footnotetext{
${ }^{12}$ Este grupo é composto por representantes de 15 países e conta com a presença de Renato Maluf, o único representante brasileiro neste Painel.

${ }^{13}$ Neste ano a FAO (2013) estima um aumento de $7 \%$ na produção de cereais no mundo em relação a 2012. No entanto, 34 países continuam necessitando de assistência alimentar externa, entre os quais 27 se localizam na África.
} 
como: o fortalecimento dos processos de produção e a criação de condições para a heterogeneidade dos pequenos produtores se inserirem nos mercados - agricultura em pequena escala produz $80 \%$ dos alimentos consumidos em muitos países em desenvolvimento; o estabelecimento de mecanismos de controle de preços dos insumos e dos alimentos; a criação de ambiente favorável de governança por parte dos poderes públicos na moderação entre os setores públicos e atores privados que atuam no sistema alimentar; e o estímulo aos mecanismos de compras públicas de alimentos para programas sociais e alimentação escolar como forma de aproximação entre produtores e consumidores.

Respeitados os enfoques entre os autores dos quatro documentos analisados, poder-se-ia adicionar uma gama de outras organizações $^{14}$ e cientistas renomados, cujas análises convergem em diagnósticos que apontam a necessidade da reconversão dos modelos de produção e consumo alimentar baseados, fundamentalmente, no que Marsden e Sonnino (2006) denominam de circuito face-a-face. $E$ todos destacam o papel estratégico e o potencial da agricultura familiar e camponesa, especialmente a de base agroecológica, na produção e no abastecimento para a segurança alimentar e nutricional. Por diferentes caminhos, ressaltam o que também afirma Maluf (2010), que a crise do sistema alimentar mostra que se equivocaram aqueles que entendiam que os mercados dariam conta de "cuidar" dos sistemas alimentares. Ao contrário, essa crise contribuiu para reforçar as teses de que os Estados precisam exercer um papel proativo na regulação dos preços e no estímulo às políticas públicas de fortalecimento dos sistemas agroalimentares nacionais e locais que assegurem o direito à alimentação de qualidade para toda população.

\section{EMERGÊNCIA E POTENCIAIS DA AGRICULTURA FAMILIAR}

No Brasil, a partir dos anos 1980 incorporou-se o termo familiar a um amplo modo de reprodução social que convencionalmente vinha sendo chamado de agricultura, ou agricultura acrescido de algum adjetivo. Desde então, gradualmente, a agricultura familiar passou a constituir-se em um tema que assume importância crescente nos diferentes âmbitos de debate, tanto no meio político como acadêmico. Segundo Wanderley (2009), entre os fatores que contribuíram para essa emergência encontram-se a

\footnotetext{
${ }^{14}$ A FIAN internacional (www.fian.org), a Action Aid Internacional (www.actionaid.org) e a GRAIN (www.grain.org) produzem e divulgam análises similares em torno dos impactos das mudanças que vêm ocorrendo na agricultura e na segurança alimentar e nutricional.
} 
mobilização e pressão dos movimentos sociais para transformar essa em uma questão da sociedade, mas houve também a efervescência da produção acadêmica em estudos que ajudaram a reposicionar a compreensão do lugar da agricultura familiar no contexto brasileiro. Na mesma linha de pensamento Schneider aponta que

A emergência da expressão agricultura familiar na literatura brasileira parece ocorrer, quase simultaneamente, em duas esferas distintas, no início da década de 1990. De um lado, no campo político, a adoção da expressão parece estar relacionada aos debates que os movimentos sociais, especialmente o sindicalismo rural ligado à Central Única dos Trabalhadores (CUT), tiveram nas discussões acerca do espaço e o papel dos pequenos produtores rurais, especialmente os da região Sul do Brasil, no processo de integração comercial e econômica dos países que formam o Mercosul e, do outro, por intermédio de alguns trabalhos acadêmicos que passaram a buscar novos referenciais teóricos e analíticos, no referido período, e que introduziram a expressão (SCHNEIDER, 2009, p. 34).

Em meio à modernização da agricultura, os pequenos agricultores corriam o risco de ficarem à margem dos processos de integração comercial e de produção agropecuária que se configuravam e que certamente influiriam nos rumos futuros da agricultura da região. Assim, "a expressão agricultura familiar surge como uma noção de convergência e unificadora dos interesses dos pequenos proprietários rurais" (SCHNEIDER, 2009, p. 34-35) mobilizados pelo sindicalismo rural, cujas ações eram bastante fragmentadas, de modo que "esse movimento constitui-se em marco decisivo para a unificação do discurso em defesa dos interesses dos agricultores familiares" em torno desta nova categoria síntese forjada pelos movimentos sociais do campo. Embora essa categoria tenha obtido reconhecimento nas últimas décadas, de acordo com Picolotto (2009), a luta para serem compreendidos como sujeitos de direitos é antiga entre os agricultores brasileiros. 
Observa-se que a discussão sobre agricultura familiar na Europa e na América do Norte alcançou expressão alguns anos antes. Num debate que se tornou importante entre fins dos anos de 1970 e início dos anos de 1990, os argumentos em torno da capacidade (e até superioridade) produtiva da agricultura familiar eram recorrentes. Abramovay (1998) argumenta que houve elementos político-institucionais que ajudaram a viabilizar econômica e socialmente esta forma de produção. Pois, permitiram que os agricultores alcançassem melhores patamares tecnológicos e patrimônio físico, por meio do incentivo creditício do Estado que estimulou o incremento da produção agrícola via a modernização da agricultura na sociedade cada vez mais urbanizada.

Friedmann (1978) argumenta, num estudo de caráter histórico, que a forma familiar se tornou mais competitiva que a empresarial, tendo em vista a flexibilidade do trabalho da família e da forma de reprodução simples do capital, nos termos de Marx. Diferente da agricultura empresarial, calcada na reprodução ampliada, a forma familiar não buscaria a mais-valia e produziria alimentos a preços mais baratos. Num espectro distinto, mas ainda em torno do marxismo, para Mann e Dickinson (1978) o capital teria que enfrentar obstáculos naturais, riscos climáticos e possíveis pragas. Diante disso as formas familiares seriam mais maleáveis para dar conta da produção alimentar ${ }^{15}$.

Novos estudos procuram demonstrar que a razão produtivista não explica o porquê dos agricultores familiares optarem por estratégias diversas dentro e fora da agricultura, mantendo-se no meio rural (ELLIS, 2000; SCHNEIDER, 2009; CONTERATO et al., 2010) e criando maneiras de organizar suas vidas conforme processos sociais emergentes de desenvolvimento rural (MARSDEN, 1992; PLOEG; MARSDEN, 2008). Tais atributos trazem novos enfoques sobre a capacidade de ação dos agricultores familiares, ainda que $o$ ambiente social e econômico seja sempre um condicionante das estratégias. Neste sentido, mesmo que o papel do Estado tenha se modificado mais recentemente - num momento pós"revolução verde" - mas sua importância na regulação e na orientação de políticas públicas permanece.

A categoria agricultor familiar passou a ocupar centralidade nos debates teóricos e diversos estudos trazem explicações sobre a permanência das famílias no espaço rural, renovando o debate e permitindo explanações sobre as definições em torno da agricultura

\footnotetext{
${ }^{15}$ Goodman et al. (1990) realizaram uma leitura kautskyana do tema, mostrando que paulatinamente a indústria se apropriava e substituía processos/elementos naturais por processados.
} 
familiar - mais recentemente "agriculturas familiares", expressão que no país parece conceder primazia à diversidade social rural.

Junto com essa definição de ordem conceitual houve, sobretudo, nas duas últimas décadas um expressivo avanço nas definições de ordem normativa e operacional da agricultura familiar. Em 1996 o Estado ${ }^{16}$ brasileiro cedeu às pressões sociais do campo e criou o Programa Nacional de Apoio à Agricultura Familiar (PRONAF), com linhas de crédito específicas para os agricultores familiares. $\mathrm{Na}$ sequência surgiram leis que visam definir e regulamentar organizações e atividades de produção e comercialização da agricultura familiar. Entre elas encontra-se a Lei Federal 11.326/2006, que define como empreendedor familiar e agricultor familiar aquele que pratica atividades no meio rural, atendendo, simultaneamente, aos seguintes requisitos:

I - não detenha, a qualquer título, área maior do que 4 (quatro) módulos fiscais; II - utilize predominantemente mão de obra da própria família nas atividades econômicas do seu estabelecimento ou empreendimento; III tenha renda familiar predominantemente originada de atividades econômicas vinculadas ao próprio estabelecimento ou empreendimento; IV - dirija seu estabelecimento ou empreendimento com sua família (BRASIL, 2006a, art. 3ํ).

No mesmo período surgiram esforços mais voltados à definição da agricultura familiar na ordem operacional, inclusive demandados pelo próprio Estado, em vista de especificar e facilitar a implementação de políticas públicas de crédito e outras aos diferentes segmentos e grupos populacionais rurais. Foi assim que Guanziroli et al. (1996) caracterizaram a agricultura familiar a partir de suas relações de produção e construíram as tipologias de agricultores capitalizados, em processo de capitalização, em

\footnotetext{
${ }^{16}$ Com base no censo agropecuário de 1985 e 1995/96, estudos do INCRA/FAO definem agricultura familiar a partir de três características centrais: "a) a gestão da unidade produtiva e os investimentos nela realizados são feitos por indivíduos que mantêm entre si laços de sangue ou de casamento; b) a maior parte do trabalho é igualmente fornecida pelos membros da família; c) a propriedade dos meios de produção (embora nem sempre da terra) pertence à família e é em seu interior que se realiza sua transmissão em caso de falecimento ou de aposentadoria dos responsáveis pela unidade produtiva." (INCRA/FAO, 1996, p. 4).
} 
descapitalização e descapitalizados. Na mesma direção, Kageyama, Bergamasco e Oliveira (2001) constituíram as tipologias de agricultor assentado, exclusivamente familiar, familiar com contratado ou "misto" e não familiar ou patronal. No geral, essas tipologias foram incorporadas pelo Estado brasileiro ${ }^{17}$ e passaram a orientar 0 direcionamento das políticas públicas para a agricultura familiar.

Mesmo que as definições conceituais, normativas e operacionais não deem conta de abranger a riqueza e diversidade de formas organizativas sociais que compõem o rural brasileiro, conforme menciona Wanderley (2009), de alguma forma estas três dimensões interagem o tempo todo com as concepções e formulações que ocorrem nos âmbitos acadêmicos, sociais e do Estado, de modo a confirmar e fortalecer a identidade da agricultura familiar como categoria política e social.

Um dos mais difundidos atributos da agricultura familiar é a sua capacidade e importância na produção de alimentos. Essa característica é muitas vezes usada para ressaltar sua relevância social, econômica e mesmo justificar políticas públicas para apoiá-la. Indiscutivelmente, a agricultura familiar é a grande responsável pelos produtos da cesta básica brasileira, conforme evidencia o Censo Agropecuário Brasileiro (2006), mas seu potencial não se reduz apenas à produção de alimentos.

Cabe recordar que o debate sobre desenvolvimento rural tem se voltado a temáticas novas, tais como a multifuncionalidade da agricultura (ou do espaço rural), sua sustentabilidade ambiental e sua força na geração de divisas. Sonnino et al. (2008) demonstram que no que se refere às áreas rurais e sua interconexão com o tema da sustentabilidade, três são os vetores interpretativos significativos que orientam os debates (e moldam planejamentos e políticas públicas). Primeiro, o paradigma agroindustrial, que não considera a finitude do ambiente nem o toma como problema, apostando na especialização, na escala produtiva e na relação com a indústria e a ciência. Segundo, a visão pós-produtivista, que reforça o caráter da paisagem e do consumo simbólico do rural, apostando num modelo de conservação da natureza e nos atributos estéticos do espaço. Ambos os paradigmas, conforme Sonnino et al. (2008), marginalizam a agricultura, cada um ao seu modo: o primeiro a torna mero insumo e elo numa cadeia agroindustrial; o segundo desconsidera o tema da produção alimentar.

17 O Censo Agropecuário 2006, realizado pelo Instituto Brasileiro de Geografia e Estatística (IBGE), apresentou pela primeira vez a categoria agricultura familiar em suas estatísticas. 
O terceiro paradigma é entendido pelos autores como o mais adequado por apostar na dimensão produtiva e sustentável do rural e da agricultura familiar para o qual ambos teriam um papel crucial nas sociedades: produzir alimentos, preservar a paisagem, auxiliar na manutenção ambiental, manter o campo povoado e preservar tradições. O desenvolvimento rural sustentável, conforme os autores, define-se como "[...] desenvolvimento fundamentado territorialmente que redefine a natureza, enfatizando a produção de alimentos e a agroecologia e que recoloca o papel socioambiental da agricultura como um relevante agente na sustentabilidade das economias e culturas rurais" (SONNINO et al., 2008, p. 31 - tradução dos autores(as)).

A partir das pesquisas antes mencionadas é preciso observar uma mudança de foco que pode ser percebida nos estudos rurais recentes, especialmente em sociologia e antropologia. Da antiga sociologia rural apareceram áreas como a sociologia da agricultura e dos processos sociais agrários (TAVARES DOS SANTOS, 1991; SCHNEIDER, 1997), procurando renovar o papel do rural e do agrícola nas sociedades contemporâneas. Nos últimos anos, a sociologia e a antropologia, preocupadas com a alimentação, fazem convergir esforços analíticos que destacam a importância da questão agroalimentar num mundo cada vez mais urbano, com tendências alimentares que primam pela cientifização, a saudabilidade, a gastronomização dos alimentos (BARBOSA, 2009), a valorização da origem dos alimentos (CRISTÓVÃO, 2002), a qualidade nutricional e sanitária (GOODMAN, 2003), bem como o sabor e as tradições alimentares.

Os dados do Censo Agropecuário 2006 reforçam o papel

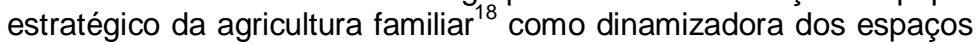
rurais. Demonstram que ela cumpre um papel proeminente de produção para o autoconsumo, mas também reforçam sua importância socioeconômica e para a segurança alimentar e nutricional. Dos 5.175 .636 estabelecimentos agropecuários, 84,4\% são reconhecidos como de agricultura familiar e ocupam $24 \%$ da área de terra.

\footnotetext{
${ }^{18}$ Agricultura familiar segundo a definição da Lei Federal 11.326/2006.
} 
Tabela 1 - Número e área dos estabelecimentos agropecuários, por agricultura familiar ou não familiar - Brasil - 2006

\begin{tabular}{l|r|r|c|r}
\hline \multirow{2}{*}{ CONDIÇÃO } & \multicolumn{2}{|c|}{ NÚMERO DE } & \multicolumn{2}{c}{ ÁREA DOS } \\
& \multicolumn{1}{c}{ ESTABELECIMENTOS } & \multicolumn{1}{c}{ ESTABELECIMENTOS } \\
\cline { 2 - 5 } & \multicolumn{1}{c}{ Abs. } & \multicolumn{1}{c}{ Abs. } & $\%$ \\
\hline Agricultura familiar & 4.366 .267 & 84,4 & 80.102 .694 & 24,0 \\
Não familiar & 809.369 & 15,6 & 253.577 .343 & 76,0 \\
Total & 5.175 .636 & 100,0 & 333.680 .037 & 100,0 \\
\hline
\end{tabular}

Fonte: IBGE - Censo Agropecuário 2006.

Mesmo se desenvolvendo em menos de $1 / 4$ da área ocupada, a agricultura familiar respondeu por 33,2\% do valor total da produção no ano de 2006. Isso demonstra que ela produz para o autoconsumo e gera excedentes para o mercado que contribuem na dinamização da economia e na geração do Produto Interno Bruto (PIB).

Ao analisar alguns de seus produtos mais típicos pode-se dimensionar a importância da agricultura familiar na dieta alimentar e na SAN dos brasileiros, como o arroz, o feijão, o milho e a mandioca. Ela está voltada, primordialmente, para o abastecimento interno, o que reforça a sua consonância com os objetivos da segurança alimentar e nutricional.

Tabela 2 - Percentual de estabelecimentos agropecuários, da quantidade produzida pela agricultura familiar e não familiar e tipo de produção vegetal Brasil - 2006

\begin{tabular}{l|c|c|c|c}
\hline \multirow{2}{*}{$\begin{array}{c}\text { Tipo de produção } \\
\text { vegetal }\end{array}$} & \multicolumn{2}{|c|}{$\begin{array}{c}\text { Percentual de } \\
\text { estabelecimentos } \\
\text { agropecuários }\end{array}$} & \multicolumn{2}{c}{$\begin{array}{c}\text { Percentual da quantidade } \\
\text { produzida (Quilogramas) }\end{array}$} \\
\cline { 2 - 5 } & $\begin{array}{c}\text { Agricultura } \\
\text { familiar }\end{array}$ & $\begin{array}{c}\text { Agricultura não } \\
\text { familiar }\end{array}$ & $\begin{array}{c}\text { Agricultura } \\
\text { familiar }\end{array}$ & $\begin{array}{c}\text { Agricultura } \\
\text { não familiar }\end{array}$ \\
\hline Arroz em casca & 89,4 & 10,6 & 33,1 & 66,9 \\
Feijão preto & 90,1 & 9,9 & 76,2 & 23,8 \\
Feijão de cor & 89,0 & 11,0 & 53,5 & 46,5 \\
Feijão fradinho & 90,3 & 9,7 & 83,8 & 16,2 \\
Mandioca & 90,6 & 9,4 & 83,2 & 16,8 \\
Milho em grão & 88,4 & 11,6 & 45,6 & 54,4 \\
Café canephora & 84,4 & 15,6 & 55,1 & 44,9 \\
Galinha & 85,9 & 14,1 & 51,2 & 48,8 \\
\hline Fonte: IBGE - Censo Agropecuário 2006. & & &
\end{tabular}

Fonte: IBGE - Censo Agropecuário 2006. 
Além da produção de alimentos, que é extremamente relevante, a agricultura familiar é responsável pelo "rural com gente" - expressão que sugere um espaço de vida e de trabalho, de cultura e diversidade, para além de um rural meramente enquanto local de produção. O rural para este segmento da população é lugar de moradia, de vida, de produção, da sociabilidade, enfim, o lugar da família (WANDERLEY, 2000). Ela está presente nos mais diversos espaços rurais e ocupa a maioria das pessoas nos estabelecimentos agropecuários, apesar de ocupar pequena extensão de área de terra e acessar volumes de crédito relativamente pequenos para se viabilizar. No Brasil, os estabelecimentos agropecuários ocupam 16.568.205 pessoas, destas $74,4 \%$ estão em estabelecimentos familiares (IBGE, 2006).

Segundo Wanderley (2000), diferentemente dos latifúndios que possuem uma relação absenteísta, despovoadora e predatória do espaço rural -, a agricultura familiar povoa o campo e anima sua vida social. Para a autora:

as perspectivas favoráveis da produção agrícola local e de suas atividades correlatas (especialmente as vinculadas aos processos de transformação e de comercialização), que garantam um nível de renda socialmente adequado à família; e a oferta de empregos não-agrícolas, no meio rural ou nas cidades próximas, de forma a gerar alternativas de ocupação para alguns membros da família e a favorecer a pluriatividade de outros (WANDERLEY, 2000, p.35).

Tanto os dados sobre a produção alimentar quanto aqueles sobre a ocupação do pessoal não deixam dúvida sobre o papel econômico e social da agricultura familiar, bem como sobre a importância de se estimular a permanência das pessoas no meio rural e de promover formas mais sustentáveis de desenvolvimento, com qualidade de vida no meio rural e nas cidades.

\section{A RELAÇÃO ENTRE AGRICULTURA FAMILIAR E A SEGURANÇA ALIMENTAR E NUTRICIONAL}

Nos últimos anos diversos autores têm escrito sobre a relação entre a agricultura familiar e a SAN. Um elemento imbricado 
nesta relação é a complementariedade entre as práticas de produção para 0 autoconsumo e para 0 mercado, pois a produção para autoconsumo gera excedentes que são disponibilizados para outros consumidores, assegurando a sua segurança alimentar e nutricional (WANDERLEY, 2009; GAZOLLA; SCHNEIDER, 2007; SABOURIN, 2009). E o fortalecimento das cadeias curtas e de proximidade favorece a interconexão entre a produção para o autoconsumo e a inserção de parte dessa produção nos mercados (MALUF, 2007; WILKINSON, 2011). Essas são algumas das muitas práticas que possibilitam a reprodução social de milhares de agricultores familiares no cumprimento de sua vocação de produzir e ofertar alimentos de qualidade para as mesas dos consumidores brasileiros.

Igualmente se avançou nos debates que culminaram na noção que explicita o entendimento de segurança alimentar e nutricional como:

a realização do direito de todos ao acesso regular e permanente a alimentos de qualidade, em quantidade suficiente, sem comprometer o acesso a outras necessidades essenciais, tendo como base práticas alimentares promotoras da saúde que respeitem a diversidade cultural e que sejam ambiental, cultural, econômica e socialmente sustentáveis. (BRASIL, 2006b, art. 3ํ).

Entre os componentes que ficam salientes nesta compreensão Conti (2013) destaca que: a acessibilidade traz a garantia do acesso físico e econômico aos alimentos; a disponibilidade requer alimentos em quantidade suficiente durante todo o tempo, mas realça a sua qualidade nutricional e livre de contaminação por produtos prejudiciais à saúde humana; a aceitabilidade cultural acentua a importância de se respeitar os hábitos e costumes alimentares nos contextos específicos das pessoas; e a sustentabilidade enfatiza a importância da alimentação com todas as características anteriores serem projetadas para garantir o bem viver das atuais e das próximas gerações, com uso racional dos recursos naturais. Estes componentes da SAN são interdependentes e precisam ser considerados conjuntamente nas análises sociais e na composição dos sistemas alimentares.

Especialmente relacionado à qualidade e à sustentabilidade estudos recentes da Articulação Nacional de Agroecologia (ANA, 
2010) localizam cinco interfaces entre a agroecologia e a SAN: diversificação da produção de alimentos e agrobiodiversidade; estabelecimento de novas relações de mercado; resgate de culturas alimentares; educação alimentar e para o consumo; e políticas públicas e mercados institucionais. Isso não só mostra a diversidade de práticas agrícolas no meio rural, mas também explicita o potencial e a relação indissociável entre a segurança alimentar e nutricional e a produção agroecológica de alimentos, o que agrega qualidade à produção e ao consumo alimentar (CONTI, 2013).

Outro fator relevante é que no processo de construção da Política e do Sistema Nacional de Segurança Alimentar e Nutricional há várias diretrizes que privilegiam os circuitos curtos de produção, distribuição e consumo alimentar com base na matriz agroecológica (BRASIL, 2011). Para tanto, entende-se que o mercado não pode autorregular-se, pois a alimentação não é uma commodity qualquer para ser comercializada na bolsa de valores, mas envolve direitos e interesses que ultrapassam o simples cálculo econômico e o ajuste de oferta e demanda.

Nesse cenário destaca-se o papel do Estado - nas esferas federal, estadual e municipal - como formulador e implementador de políticas públicas com participação social e na construção e regulação de mercados. Nos últimos anos tem crescido o estímulo à produção da agricultura familiar para abastecer programas públicos, como é caso do Programa de Aquisição de Alimentos (PAA), o Programa Nacional de Alimentação Escolar (PNAE), restaurantes populares, cozinhas comunitárias e feiras. Dessa forma as políticas públicas exercem um papel importante ao viabilizar investimentos e garantir mercados através das compras públicas de alimentos para serem repassados à população por meio dos programas de proteção e promoção social, ao mesmo tempo em que contribuem para viabilizar a agricultura familiar a partir de diferentes fontes de renda.

A seguir apresentam-se dois casos que evidenciam realidades distintas - Toledo, um município num território cujo tecido social é tipicamente marcado pela agricultura familiar, e Contagem, localizado em uma região metropolitana -, que possuem em comum a implementação e o fortalecimento de programas e ações que potencializam a agricultura familiar e a segurança alimentar e nutricional, através da introdução de uma diversidade de iniciativas que estreitam os laços entre a produção, a distribuição e o consumo alimentar. 


\subsection{Interconexões entre Segurança Alimentar e Nutricional e Agricultura Familiar em Toledo}

O município de Toledo situa-se na região Oeste do Paraná, com 116.774 habitantes, dos quais $80 \%$ vivem na área urbana. Sua estrutura fundiária é constituída por 5.279 propriedades com até dois módulos rurais, 418 entre dois e quatro módulos e 113 propriedades com mais de quatro módulos rurais, caracterizando-se como um município tipicamente de agricultura familiar e produção diversificada para o autoconsumo e os mercados.

O poder público compôs um arranjo integrado por equipamentos públicos de SAN e iniciativas de dinamização da agricultura familiar. $O$ eixo em torno do qual se desenvolvem as ações de SAN é a Cozinha Social, para onde convergem os produtos agrícolas oriundos das compras públicas e de onde parte a alimentação preparada para os restaurantes populares, escolas e demais espaços da rede de proteção socioassistencial.

A Cozinha Social foi inaugurada em 2006 e gradualmente foram construídos cinco restaurantes populares localizados em bairros industriais, que servem, em média, 500 refeições diárias cada $^{19}$. Também são produzidas e distribuídas refeições diárias para 14 escolas municipais e lanches para 16 creches, 17 grupos de idosos, 23 grupos de crianças atendidos pela Pastoral da Criança e nove postos de saúde. A Cozinha Social possui uma panificadora e uma unidade de beneficiamento de soja que produz suco de soja.

A alimentação preparada na Cozinha Social é acondicionada e distribuída em caixas térmicas, por uma frota de seis veículos, para todas as unidades que a distribuem da seguinte forma: os restaurantes populares distribuem diariamente 1.800 refeições; as escolas fornecem 12.000 refeições e 2.000 pães por dia; as creches distribuem 2.500 lanches por dia; os grupos de idosos acessam a 6.000 lanches por semana destinados aos Centros de Revitalização da Terceira Idade; a Pastoral da Criança repassa 600 lanches por mês e outros projetos sociais recebem 1.000 lanches por dia; os Centros de Referência em Assistência Social (CRAS) distribuem 1.000 lanches por dia nas atividades que ocorrem nos turnos inversos; eventos diversos promovidos pela administração municipal consomem, em média, 3.000 lanches por semana. Além destas, são fornecidas 100 marmitas diárias aos trabalhadores do

\footnotetext{
${ }^{19}$ Em 2010 o preço por refeição era de $\mathrm{R} \$ 2,00$ per capita e representava cerca de $30 \%$ do seu custo médio, sendo que a diferença é subsidiada pelo orçamento do município.
} 
serviço público da área de infraestrutura e 300 para a associação do Bairro onde se localiza a Cozinha Social.

Para abastecer esta ampla rede alimentar o município possui projetos de fomento à produção que visam alcançar a produção e consumo de 150 toneladas de maçã e 42 mil litros de suco de uva por ano nos próximos anos, além da produção de 100 toneladas anuais de carne ovina, uma grande diversidade de verduras, legumes, frutas e panificados para viabilizar o consumo nesses espaços articulados em torno da Cozinha Social.

O Programa de Aquisição de Alimentos (PAA) e o Programa Nacional de Alimentação Escolar (PNAE) contribuíram com aproximadamente $30 \%$ do fornecimento de alimentos da agricultura familiar transformados e distribuídos a partir da Cozinha Social em 2010 e subiram para quase $50 \%$ em 2011.

Observa-se que, aos poucos, o PAA e o PNAE se tornam uma estratégia de reorganização da produção e de alavancar a agricultura familiar, incentivando a independência, de tal forma que os agricultores acessem outras formas de mercado, além deste mercado institucional, o que já vem sendo feito por diversos deles. Atualmente existem 300 agricultores cadastrados que produzem e fornecem ao PAA e uma cooperativa com 77 agricultores familiares associados que fornecem a maioria dos produtos que compõem a dieta alimentar do PNAE no município.

Tais iniciativas empreendidas pelo poder público demonstram que o PAA, o PNAE e outros projetos locais, em Toledo, são indutores de organização social e econômica, geram dinâmicas sociais e renda que contribuem para dinamizar a agricultura familiar e aperfeiçoa a qualidade dos alimentos disponibilizados aos consumidores na rede escolar, socioassistencial, nos restaurantes populares, feiras e mercado em geral. Entretanto, quase toda produção que abastece este circuito alimentar é baseada no modelo convencional de agricultura, com utilização de insumos e agrotóxicos pouco compatíveis com a finalidade desses equipamentos de alimentação e nutrição. A produção agroecológica, que poderia ser uma alternativa a ser reforçada, permanece periférica e recebe pouco estímulo público para tornar-se uma estratégia de produção e consumo de alimentos saudáveis no município. Ainda que estejam baseadas em um modelo convencional de produção, as ações e os programas que vêm sendo implementados no município estimulam as cadeias curtas de produção, abastecimento e consumo alimentar e identificam o município entre aqueles que se encontra em um processo crescente de construção de um sistema de segurança alimentar e nutricional em estreita relação com o fortalecimento do 
desenvolvimento rural. O que distingue este de muitos outros municípios brasileiros é a opção deliberada do poder público pela introdução de mecanismos que aproximam a produção e o consumo alimentar estimulados por políticas públicas.

Examinando-se estes processos, observa-se que eles são promovidos pelo poder público, com baixa incidência da participação social dos agricultores familiares e suas organizações que produzem e fornecem os alimentos, bem como das entidades socioassistenciais que os recebem, remetendo a um questionamento sobre a viabilidade e a sustentabilidade de tais iniciativas a médio e longo prazo para o desenvolvimento rural e para a emancipação socioeconômica dos sujeitos nelas envolvidos. Nota-se que o desenvolvimento rural é um tema motriz para gerar elos e experiências coletivas com efeitos positivos. O Estado continua sendo um ente chave nesta indução, embora os dados mostrem que os atores sociais constroem modos de articulação particulares para resolverem problemas considerados cruciais. Sob este ponto de vista, a produção de alimentos e toda a rede de relações estabelecida sugere estar enfrentando os desafios predicados à noção de desenvolvimento rural sustentável em que a natureza, a economia e a sociedade precisam estar implicadas para que os projetos sejam eficazes (SONNINO et al., 2008).

\subsection{Segurança Alimentar e Nutricional e Agriculturas em Contagem}

O município de Contagem integra a região metropolitana de Belo Horizonte, com 625.000 habitantes e ocupa a terceira posição entre os municípios mais populosos de Minas Gerais. Sua extensão territorial é de $195 \mathrm{~km}^{2}$, caracterizando-se por ser um município eminentemente urbano. Conforme os gestores públicos, as políticas e programas de segurança alimentar e nutricional, introduzidas a partir de 2005, estão contribuindo para forjar uma 'nova cultura' de políticas públicas em Contagem. Elas ultrapassam a dimensão estritamente econômica e alcançam as dimensões de trocas e de reprodução biológica e social, constituindo-se em um instrumento de desenvolvimento social. Isso se mostra na introdução de ações e programas, como cozinhas comunitárias, bancos de alimentos, educação alimentar e agricultura urbana, ancorados em estruturas institucionais como a Coordenadoria de Segurança Alimentar Nutricional e Abastecimento, e visibilizadas em um Plano Municipal de SAN com ações políticas e dotação orçamentária específica. 
A implantação das cozinhas comunitárias, localizadas nos bairros Nova Contagem e Eldorado, com densidade de população vivendo em situação de vulnerabilidade social e alimentar, servem 700 refeições diárias. As famílias que acessam as refeições são cadastradas e acompanhadas pelos Centros de Referência em Assistência Social, sediados próximos às cozinhas. Cada comensal contribui com um valor simbólico por mês para garantir seu almoço e jantar. Ambas são parcialmente abastecidas pelo Banco Municipal de Alimentos e com alimentos oriundos da agricultura familiar, urbana e periurbana, complementados por aquisições feitas no mercado.

O município possui um Programa de Educação Alimentar e Nutricional, viabilizado por recursos federais e municipais e em estreita interface com as cozinhas comunitárias, que capacitam agentes multiplicadores para melhorar a dieta, resgatar hábitos alimentares saudáveis e promover a saúde da população. Em torno de 650 manipuladores de alimentos, agentes comunitários de saúde, alunos da rede pública de educação, funcionários públicos e pessoas atendidas pelos programas da rede socioassistencial são abrangidos por este programa, além das famílias visitadas por esses agentes. $\mathrm{E}$ um programa importante no suporte a estas iniciativas é o Banco de Alimentos, com capacidade de estocagem de 80 toneladas, que arrecada e distribui alimentos através da rede socioassistencial.

Contagem ainda é um município basicamente consumidor de alimentos. Mas, este quadro vem se alterando, aos poucos, com o incremento da agricultura urbana, periurbana e familiar, que amplia sua produção e oferta de alimentos. E a equipe gestora da Coordenadoria de SAN avalia que o município tem potencial de produzir bem mais alimentos no espaço urbano e periurbano na medida em que se avançar na formulação e implementação de estratégias que potencializem a produção alimentar na região metropolitana. O Ponto da Roça - que é um espaço de comercialização direta de produtos agroecológicos provenientes da agricultura familiar, periurbana e urbana do município e da região - é organizado pela Prefeitura Municipal e está em processo de expansão. No entanto, é o Programa de Aquisição de Alimentos (PAA), através da modalidade Compra com Doação Simultânea, operacionalizada pelo município, que está impulsionando e dinamizando os circuitos curtos de produção, abastecimento e consumo de alimentos, através da aquisição de 247 toneladas de alimentos por ano de agricultores familiares do município e de outros 14 municípios da região. Esses alimentos são destinados ao Banco de Alimentos que, por sua vez, abastece as cozinhas comunitárias e a rede socioassistencial do município. 
Esta é uma novidade institucional que merece destaque para a análise. O Estado tem realizado esforços para consolidação da agricultura familiar, o que tem gerado externalidades relevantes não apenas do ponto de vista produtivo, mas municípios começam a apostar na manutenção do 'rural com gente' produzindo alimentos para um mercado local/regional tanto rural (observando-se 0 autoconsumo) como urbano (analisando-se todo o circuito em que os alimentos circulam para atingirem consumidores urbanos).

Outra iniciativa inovadora em políticas públicas de SAN é o Centro Municipal de Agricultura Urbana e Familiar (CEMAUF), cuja implementação resultou de deliberação da I Conferência Municipal de Segurança Alimentar Nutricional e Abastecimento. O CEMAUF apoia a criação de hortas urbanas e periurbanas para proporcionar o consumo de alimentos saudáveis às famílias, com a comercialização de seus excedentes e para 0 abastecimento das cozinhas comunitárias. Ele acompanha 350 famílias organizadas em 17 grupos situados em diferentes bairros. Em sua sede - que funciona como um centro experimental, demonstrativo e de capacitação -, cultiva-se uma grande variedade de alimentos e plantas medicinais. Parte desta produção é comercializada diretamente e a maioria é destinada ao abastecimento do Banco de Alimentos. Esta é uma experiência de organização, ainda nova, mas que possui amplo efeito de multiplicação, dado que um dos focos principais do Centro é 0 apoio às iniciativas que apresentam potencial organizativo e multiplicador, contribuindo para que se disseminem tais experiências nos bairros e no entorno da região metropolitana.

O Centro trabalha com base nos princípios da produção agroecológica, com ênfase na capacitação de lideranças sociais e na difusão de tecnologias sustentáveis, como o manejo do solo, captação de água da chuva e compostagem, além de sua incidência pedagógica e educativa. As diversas iniciativas do CEMAUF se articulam com projetos educacionais nas escolas e na assessoria às instituições que recebem alimentos do Banco de Alimentos, visando despertar e fortalecer iniciativas de hortas nas famílias e nas comunidades e ampliar o consumo de alimentos saudáveis.

Pelas características inerentes a uma cidade metropolitana, Contagem apresenta um potencial inovador das relações urbanorural na produção e consumo alimentar. As políticas públicas adotadas nos últimos anos, ainda que sejam localizadas, setoriais e pouco expressivas em volume em relação ao universo da população do município, representam um passo significativo no enfrentamento da questão do abastecimento alimentar dos médios e grandes centros urbanos. $\mathrm{E}$ as inciativas de hortas familiares, comunitárias e 
de agricultura periurbana não só incrementam a produção de alimentos no espaço urbano, mas também evidenciam a importância de ações articuladas entre o poder público e as organizações e instituições da sociedade civil na promoção da segurança alimentar e nutricional.

Entretanto, de modo similar ao que foi observado em relação a Toledo, cabe realçar que todas essas iniciativas estão calcadas na proatividade do poder público e numa postura relativamente passiva das organizações da sociedade civil que produzem, fornecem e se beneficiam desse arranjo em torno do circuito alimentar. Tal fragilidade poderia ser dirimida mediante 0 fortalecimento de ações como a educação alimentar e nutricional, o envolvimento mais ativo das atuais entidades e organizações participantes, mas também das redes alimentares como o entreposto da CEASA e outras, na formulação e execução das políticas públicas de SAN.

Neste caso, parece fazer sentido a ideia de pluralidade dos atores sociais e das "agriculturas familiares" que compõem esta diversidade social na produção e consumo de alimentos, enquanto grupos sociais que disputam oportunidades políticas e econômicas. Isto emerge no que tange às diferentes práticas de agricultura, incluindo potenciais novidades, tais como a maior participação de agricultores ecologistas em programas voltados à segurança alimentar e nutricional. Contagem exemplifica também os distintos circuitos de conexão entre atores sociais rurais e urbanos face às possibilidades de expansão da produção de alimentos que determinadas políticas de governo desencadeiam. Mais que mera reação frente a mecanismos governamentais, os atores reconstroem e redefinem suas inserções e estratégias (ELLIS, 2000) com a finalidade de induzir modificações no ambiente institucional e econômico. A territorialização das práticas, que parece estar no cruzamento entre políticas em nível federal e seus entrelaçamentos com programas municipais, sustenta também as conexões ampliadas que a alimentação promove nesta situação, haja vista a crescente importância de relacioná-la a aspectos tais como educação e sustentabilidade.

\section{CONSIDERAÇÕES FINAIS}

Nas duas últimas décadas a agricultura familiar foi reconhecida no meio político-normativo, acadêmico, social e econômico do país, mas também alcança um significado expressivo 
para viabilizar o rural com gente e estreitar as interconexões ruralurbano na produção e no consumo alimentar.

Este estudo contribuiu para mostrar que tanto no contexto internacional como no cenário brasileiro a agricultura familiar exerce um papel proeminente na produção alimentar que garante a segurança alimentar e nutricional da população. Esse potencial dinamizador se amplia à medida que o Estado cria condições de fomento ao crédito e mecanismos que favoreçam à sua inserção nos mercados formais e institucionais.

Por sua vez, também requer que os diferentes segmentos da agricultura familiar aperfeiçoem seus processos organizativos e de gestão para acessar os disputados mercados, mediante a oferta de produtos diversificados e saudáveis. Assim, em meio às contradições e pressões da agricultura moderna e pouco sustentável persistem, emergem e se fortalecem iniciativas e processos sociais que apontam para formas de produção mais sustentáveis baseadas nas cadeias curtas. Estas tendências se mostram crescentes no contexto internacional e nacional, se configuram como formas diversificadas e viáveis de constituição de sistemas agroalimentares baseados na agricultura familiar e na realização da segurança alimentar e nutricional.

A partir da literatura e dos casos de Toledo e Contagem pode-se extrair aprendizados que contribuem para o debate mais amplo sobre as interfaces entre a agricultura familiar e a SAN. Primeiro, que as áreas metropolitanas podem exercer um papel proativo em torno da viabilização de ações que unam agricultores familiares, periurbanos e famílias urbanas interessados na produção, abastecimento e consumo alimentar saudável. Toledo possui um tecido social característico de um território marcado pela forma familiar de produção, contribuindo para uma ruralidade que extravasa o espaço propriamente rural e cria sinergias com políticas públicas que favorecem o consumo oriundo de alimentos da agricultura familiar. Contagem está num espaço de urbanização densa, porém constituindo elos de ligação com o espaço periurbano e rural a partir de articulações expressivas entre atores sociais e o Estado no local.

Segundo, que o Estado tem um papel relevante na implementação de políticas e programas públicos - como PAA, PNAE, bancos de alimentos, cozinhas comunitárias, educação alimentar e projetos locais - que favoreçam as interrelações e a proximidade entre produtores e consumidores. Mesmo com abrangência de um público ainda restrito que deveria ser mais universalizado, esses equipamentos e programas estão produzindo resultados que alteram a qualidade de vida dos agricultores 
familiares e índices de SAN dos consumidores que os acessam. No entanto, o dinamismo e a participação das organizações da sociedade civil na formulação e execução de tais ações são cruciais para a sustentabilidade dessas experiências e de seu potencial transformador.

O terceiro aprendizado é que a dinamização da agricultura familiar e sua interface com os programas e ações de SAN, além de aproximar produtores e consumidores, contribui para se repensar as relações rural-urbano nas quais o tema da segurança alimentar e nutricional envolva disponibilidade de alimentos, mas também a qualidade, a tipicidade e a diversidade de acordo com os territórios e os grupos sociais e suas situações alimentares.

Por fim, ainda que sejam incipientes, os dois casos analisados apresentam um potencial inovador e dinamizador de estratégias que ajudam a concretizar os objetivos da segurança alimentar e nutricional no país. Diante da crescente demanda pela qualidade dos alimentos, políticas públicas que estimulam novas formas de produção e consumo constituem-se em respostas que cabem ser mais estudadas e valorizadas pelo seu potencial de mudanças sociais.

\section{REFERÊNCIAS}

ABRAMOVAY, R. Paradigmas do capitalismo agrário em questão. 2. ed. São Paulo: Anpocs; Hucitec, 1998.

ARTICULAÇÃO NACIONAL DE AGROECOLOGIA - ANA. Grupo de Trabalho em Soberania e Segurança Alimentar. Organizado por Silvia Amaral Rigon, et al., 1. ed. Rio de Janeiro: FASE, 2010.

BARBOSA, L. Tendências da alimentação contemporânea. In: PINTO, M. L.; PACHECO, J. K. (Org.). Juventude, Consumo \& Educação 2. Porto Alegre: ESPM, 2009, p.15-64.

BRASIL. Presidência da República. Lei 11.346, de 15 de setembro de 2006b. Lei Orgânica de Segurança Alimentar e Nutricional (LOSAN).

em:

http://www.planalto.gov.br/ccivil_03/_ato2004-

2006/2006/lei/l11346.htm. Acesso em: 25 ago. 2013

BRASIL. Presidência da República. Lei № 11.326, de 24 de Julho de 2006a. Estabelece as diretrizes para a formulação da Política Nacional da Agricultura Familiar e Empreendimentos Familiares Rurais. 
http://www.planalto.gov.br/ccivil_03/_ato2004-

2006/2006/lei/l11326.htm. Acesso em: 27 ago. 2013.

BRASIL. Decreto $n^{\circ}$ 7.272, de 25 de agosto de 2010 . Regulamenta a Lei $n^{\circ} 11.346$, de 15 de setembro de 2006, que cria o Sistema Nacional de Segurança Alimentar e Nutricional-SISAN. Brasília, 2010.

BRASIL. Ministério do Desenvolvimento Social e Combate à Fome (MDS). Fome Zero: uma história brasileira. Brasília: MDS, 2010.

- Câmara Interministerial de Segurança Alimentar e Nutricional. Plano Nacional de Segurança Alimentar e Nutricional: 2011/2015. Brasília: MDS, CONSEA, 2011.

CONSELHO NACIONAL DE SEGURANÇA ALIMENTAR E NUTRICIONAL - CONSEA. Princípios e Diretrizes de uma Política de Segurança Alimentar e Nutricional. Textos de referência da II Conferência Nacional de Segurança Alimentar e Nutricional. CONSEA. Brasília, julho de 2004.

CONTERATO, M. A.; SCHNEIDER, S.; WAQUIL, P. D. Estilos de agricultura: uma perspectiva para a análise da diversidade da agricultura familiar. Ensaios FEE, v. 31, p. 149-186, 2010.

CONTI, I. L. Interfaces entre direito humano à alimentação adequada, soberania alimentar, segurança alimentar e nutricional e agricultura familiar. In: CONTI, I. L. (Org.). Convivência com o Semiárido Brasileiro: autonomia e protagonismo social. Brasília: Editora IABS, 2013.

CRISTÓVÃO, A. Mundo Rural: entre as representações (dos urbanos) e os benefícios reais (para os rurais). In: RIEDL, M.; ALMEIDA, J. A.; BARBOSA, A. L. Turismo rural: tendências e sustentabilidade. Santa Cruz do Sul: Ed. UNISC, 2002.

ELLIS, F. Rural livelihoods and diversity in developing countries. Oxford: Oxford University, 2000.

FAO. Food security and climate change. HLPE, 2012. A report by the High Level Panel of Experts on Food Security and Nutrition of the Committee on World Food Security, Rome 2012a.

FAO. Social Protection for Food Security. HLPE, 2012. A report by the High Level Panel of Experts on Food Security and Nutrition of the Committee on World Food Security, Rome 2012b. 
FAO. Crop prospects and food situation. Disponível em: http://www.fao.org/docrep/018/aq114e/aq114e.pdf. Acesso em: 14 jul. 2013.

FAO. El estado mundial de la agricultura y la alimentación. Disponível em: http://www.fao.org/publications/e-book-collection/en/. Acesso em: 14 jul. 2013.

FIAN Internacional. El acaparamiento de tierras y la nutricion 2010. Editado pelo Observatório Internacional pelo Direito à Alimentação e Nutrição. Disponível em: https://www.fao.org.br/cdptarfp.asp. Acesso em: 10 jul. 2012.

FRIEDMANN, $\mathrm{H}$. Simple commodity production and wage labour in the American Plains. Journal of Peasant Studies, v. 6, n. 1, p. 71100, 1978.

GAZOLLA, M.; SCHNEIDER, S. A produção da autonomia: os "papéis" do autoconsumo na reprodução social dos agricultores familiares. Estudos, Sociedade e Agricultura, Rio de Janeiro, UFRRJ, v. 15. p. 89-122, 2007.

GOODMAN, D.; SORJ, B.; WILKINSON, J. Das lavouras às biotecnologias. Rio: Campus, 1990.

GOODMAN, D. The quality 'turn' and alternative food practices: reflections and agenda. Journal of Rural Studies, v. 19, p.1-7, 2003.

GOODMAN, D. Agro-food studies in the 'Age of Ecology': nature, corporeality, bio-politics. Sociologia Ruralis,v. 39, n. 1, 1999.

GRAIN. The great food robbery: how corporations control food, grab land and destroy the climat. Disponível em: https://www.fao.org.br/cdptarfp.asp. Acesso em: 15 jul. 2013.

GUANZIROLI, C. E.; ROMEIRO, A.; DI SABBATO, A.; SHIKI, S.; COUTO, V. A. Perfil da agricultura familiar no Brasil: dossiê estatístico. Brasília: FAO/INCRA, 1996.

INCRA/FAO (1996). Perfil da agricultura familiar no Brasil: dossiê estatístico. Brasília. Guanziroli, C. e Cardim, S. (coord.). O novo retrato da agricultura familiar: o Brasil Redescoberto. Brasília, Convênio FAO/Incra, INCRA, 2000.

INSTITUTO BRASILEIRO DE GEOGRAFIA E ESTATÍSTICA IBGE. Censo Agropecuário 2006. Disponível em: www.ibge.gov.br/home/presidencia. Acesso em: 12 jul. 2012. 
INSTITUTO DE PROMOÇÃO DO DESENVOLVIMENTO. Perfil do mercado orgânico como processo de inclusão social. Disponível em: $\quad$ http://www.ipd.org.br/pt-br/noticia/194/perfil-do-mercadoorganico-como-processo-de-inclusao-social. Acesso em: 14 jul. 2012.

KAGEYAMA, A.; BERGAMASCO, S. M. P. P.; OLIVERIA, J.A. Uma tipologia dos estabelecimentos agropecuários a partir Do Censo de 2006. Mono. 2011.

MALUF, R. S. Segurança alimentar e nutricional: conceitos fundamentais. Petrópolis, RJ: Vozes, 2007.

. Mercados agroalimentares e a agricultura familiar no Brasil: agregação de valor, cadeias integradas e circuitos regionais. Ensaios FEE. Porto Alegre, v. 25, n. 1, p. 299-322, 2004.

Construção do SISAN, mobilização e participação social. In: Ministério do Desenvolvimento Social e Combate à Fome. Fome Zero: uma história brasileira. Brasília, DF: MDS, v. 2, p. 27-37, 2010.

MANN, S.; DICKINSON, J. Obstacles to the development of a capitalista agriculture. Journal of Peasant Studies, v. 5, n. 4, p. 466481, 1978.

MARSDEN, T. Exploring the rural sociology for the fordist transition: incorporating social relations into economic restructuring. Sociologia Ruralis. v. 32 (2/3), p. 209-230, 1992.

MARSDEN, T. K.; SONNINO, R. Beyond the divide: rethinking relations between alternative and conventional food networks in Europe. Journal of Economic Geography, v. 6, p. 181-189, 2006.

ORGANIZAÇÃO DAS NAÇÕES UNIDAS. Comitê de Direitos Econômicos, Sociais e Culturais do Alto Comissariado de Direitos Humanos/ONU - 1999. Comentário Geral no 12. Disponível em: pfdc.pgr.mpf.gov.br/Comentario. Acesso em: 10 jun. 2012.

. Pacto Internacional de Direitos Econômicos, Sociais e Culturais. Comitê de Direitos Econômicos, Sociais e Culturais. Alto Comissariado de Direitos Humanos/ONU -1966. Disponível em: www2.mre.gov.br/dai/m_591_1992.htm. Acesso em: 05 nov. 2011.

Declaração Universal dos Direitos Humanos. Disponível em: 
http://www.direitoshumanos.usp.br/counter/Onu/Sist_glob_trat/texto/t exto_1.html. Acesso em: 10 jul. 2012.

PICOLOTTO, E. A emergência dos "agricultores familiares" como sujeitos de direitos na trajetória do sindicalismo rural brasileiro. Mundo Agrário, v. 9, n. 18, p. 1-39, 2009.

PLOEG, J.D.; MARSDEN, T. Preface: exploring the rural web. In:_. (Ed.) Unfolding webs: the dynamics of regional rural development. Assen: Van Gorcum, 2008. p. vii-ix.

SABOURIN, E. Comunidades camponesas e organização social da produção. In: Camponeses do Brasil: entre a troca mercantil e a reciprocidade. Rio de Janeiro: Garamond, 2009.

SCHNEIDER, S. Da crise da Sociologia Rural à emergência da Sociologia da Agricultura: reflexões a partir da experiência norteamericana. Cadernos de Ciência \& Tecnologia, Brasília, v. 14, p. 225-256, 1997.

. Situando o desenvolvimento rural no Brasil: o contexto e as questões em debate. Revista de Economia Política, v. 30, n. 3 (119), pp. 511-531, jul./set. 2010.

A pluriatividade na agricultura familiar. 2 ed. Porto Alegre: Editora da UFRGS, 2009.

SCHUTTER, O. Agroecologia e Direito Humano à Alimentação. Relator Especial da ONU Para Direito à Alimentação, apresentado ao Conselho de Direitos Humanos - Décima sexta sessão - Item 3 da agenda "Promoção e proteção de todos os direitos humanos, direitos civis, políticos, econômicos, sociais e culturais, inclusive o direito ao desenvolvimento". Câmara Interministerial de Segurança Alimentar e Nutricional. Brasília: 2012.

SONNINO, R.; KANEMASU, Y.; MARSDEN, T. Sustainability and rural development. In: PLOEG, J.D.; MARSDEN, T. (Ed.). Unfolding webs: the dynamics of regional rural development. Assen: Van Gorcum, 2008. p. 29-52.

TAVARES-DOS-SANTOS, J. V. Crítica da Sociologia Rural e a construção de uma outra sociologia dos processos sociais agrários. Ciências Sociais Hoje, São Paulo, p. 13-51, 1991.

WANDERLEY, M. N. B. A valorização da agricultura familiar e a reivindicação da ruralidade no Brasil. Desenvolvimento e Meio Ambiente, Curitiba, n.2, p.29-37, jul/dez. 2000. 
WANDERLEY, M. N. B. Os estudos rurais no Brasil: as ciências sociais e as questões da sociedade. Apresentado no $33^{\circ}$ Encontro Anual da ANPOCS. GT 35: Ruralidade, Território e Meio Ambiente. Caxambu, outubro de 2009.

WILKINSON, J. The mingling of markets, movements and menus: the renegotiation of rural space by NGOs, social movements and traditional actors. In: GLOBALISATION: SOCIAL AND CULTURAL DYNAMICS, International Workshop, Rio de Janeiro: MINDS, 2006.

WILKINSON, J. Mercados, redes e valores. Porto Alegre: Editora da UFRGS, 2008. 